\title{
LIFECYCLE MANAGEMENT, MONITORING AND ASSESSMENT FOR SAFE LARGE-SCALE INFRASTRUCTURES: CHALLENGES AND NEEDS
}

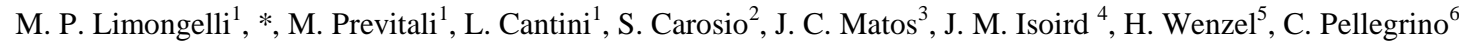 \\ ${ }^{1}$ Politecnico di Milano, Department of Architecture, Built Environment and Construction Engineering, \\ Via Ponzio 31, 20133 Milano, Italy - (mariagiuseppina.limongelli, mattia.previtali, lorenzo.cantini,)@ polimi.it \\ ${ }^{2}$ Unismart Padova Enterprise Srl, Via VIII febbraio, 2, 35122 Padova \\ ${ }^{3}$ Civil Engineering Department, Campus de Azurém, Minho University, 4800-058 Guimarães, Portugal \\ ${ }^{4}$ Fundación Tecnalia Research and Innovation Calle Geldo, Edificio 700, Parque Tecnologico de Bizkaia, 48160, Derio, Spain \\ ${ }^{5}$ Wenzel Consulting Engineers GmbH, Vienna, Austria \\ ${ }^{6}$ Università degli Studi di Padova, Ingegneria Civile, Edile ed Ambientale, Via F. Marzolo, 9 - Padova - carlo.pellegrino@unipd.it
}

KEY WORDS: Bridges, Lifecycle management, Structural Health Monitoring, performance assessment, standards

\begin{abstract}
:
Many European infrastructures dating back to ' 50 and ' 60 of the last century like bridges and viaducts are approaching the end of their design lifetime. In most European countries costs related to maintenance of infrastructures reach a quite high percentage of the construction budget and additional costs in terms of traffic delay are due to downtime related to the inspection and maintenance interventions. In the last 30 years, the rate of deterioration of these infrastructures has increased due to increased traffic loads, climate change related events and man-made hazards. A sustainable approach to infrastructures management over their lifecycle plays a key role in reducing the impact of mobility on safety (over 50000 fatalities in EU per year) and the impact of greenhouse gases emission related to fossil fuels. The events related to the recent collapse of the Morandi bridge in Italy tragically highlighted the sheer need to improve resilience of aging transport infrastructures, in order to increase the safety for people and goods and to reduce losses of functionality and the related consequences. In this focus Structural Health Monitoring (SHM) is one of the key strategies with a great potential to provide a new approach to performance assessment and maintenance over the life cycle for an efficient, safe, resilient and sustainable management of the infrastructures. In this paper research efforts, needs and challenges in terms of performance monitoring, assessment and standardization are described and discussed.
\end{abstract}

\section{INTRODUCTION}

A large number of European infrastructures are approaching the end of its design lifetime. Indeed, the construction period of a large set of infrastructures, like bridges, viaducts is dating back to ' 50 and ' 60 of the last century. In that epoch the design lifetime of infrastructures was 50 years. Since nowadays many of those infrastructures are very close to the end of life by design, or even beyond, bridges and viaducts are becoming more and more critical assets to secure mobility of people and goods. Furthermore, more recently, built infrastructure has shown faster deterioration process due to design or poor construction, which is accelerated by external factors such as increased traffic loads, climate change and natural and manmade hazards.

Maintenance actions are required to keep the asset at the desired performance level and, to achieve this aim, efficient decisions, optimizing interventions while keeping functionality at the required level, must be based on comprehensive life cycle approaches accounting for short \& long - term consequences of each considered alternative. Even if the technical aspects are only a part of the solution, being economic and social aspects two other pillars that drive the management of infrastructures, the definition of a holistic approach using progress in key enabling technologies for inspecting. monitoring, assessing, upgrading and maintaining bridges is crucial. This may also need the harmonization of different standards and codes or the definition of new protocols for life extension.

The importance of this topic is underlined by the rise of specific actions at national and international level focusing on this issue. Among the other, the Cost Action TU1406 - Quality specifications for roadway bridges, standardization at a European level (Matos, 2016) - and the Cost Action TU1402 Quantifying the value of Structural Health Monitoring (Thons et al. 2017) - developed European networks of experts working in this topic.

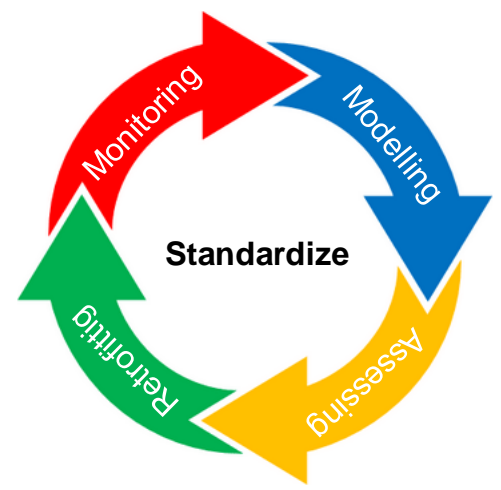

Figure 1. Bridge lifecycle

This paper presents some insights on an integrated approach for lifecycle management of bridges. The approach builds upon capitalizing the outcomes of ongoing national and international initiatives as well as the results of researches dealing with specific aspects of the lifecycle bridge management (Figure 1): (i) condition inspection and monitoring; (ii) performance modelling; (iii) performance assessment (iv) adaptive and retrofitting interventions and (v) standardization of best practices in maintenance and management of bridges.

The first part of this paper will focus on current and emerging approaches and key enabling technologies for the inspection, 
monitoring and diagnosis of the safety and serviceability of the bridge asset with a lifecycle perspective. The current state of research on performance assessment using indicators and forecast models to predict the expected life of the infrastructures is outlined. The last part of the paper will present an overview of the available guidelines and standards developed at European Level and the current needs and challenges for a sustainable and resilient infrastructure management

\section{PERFORMANCE MONITORING}

Monitoring of the structural performance plays a critical role in the structural assessment of bridges since the information provided may support decision making to optimize the management of the infrastructures over their life cycle. In order to minimise the downtime and the related consequences in terms of time loss and pollution related to the detour monitoring methods should be non-destructive and minimally invasive.

Depending on the frequency with which measures are collected, three categories of monitoring can be defined (Frýba and Pirner, 2001): short term, periodic and long term. The structural response to static or dynamic loads is measured in terms of strains, displacement, accelerations and other parameters that can be used to retrieve information about the structural performance under external actions - for example in terms of displacements under proof loading or in terms of accelerations during ambient vibration tests. Proof loading are an example of short-term monitoring whereas experimental or operational modal analyses is often used to periodically assess the structural state. The measurement of the structural response to ambient vibrations using networks of sensors permanently installed on the structure is an efficient method to monitor possible deviations of the structural behaviour from a reference condition. Several techniques have been developed by researchers to measure displacements during proof load testing: Linear Variable Differential Transformers (LVDT), GPS monitoring, Robotic total stations (RTS), geometric levelling and terrestrial laser scanning. LVDT sensor are generally used for short span bridges over accessible land and when a fixed reference below the bridge is available (Moreu et al., 2015). GPS monitoring is becoming more and more widespread for bridge displacement measurement (Wong, 2007; Tang et al., 2017; Xi et al., 2018). However, it is generally challenging to measure relatively stiff footbridge where movement ranges are modest. Robotic total stations are frequently used for the measurement of bridge displacements induced by changes of temperature or by applied loads during testing (Zhou et al., 2006). The advantage of RTS and GPS monitoring is the possibility to measure $3 \mathrm{D}$ displacement vectors. However, to obtain results with sub-millimetre accuracy, the design of the acquisition network needs to be carefully planned. Geometric levelling is used to measure differences in elevations between two or more points. Experience has shown geometric levelling to be a reliable and precise method to measure (in the order of $0.1 \mathrm{~mm}$ ) vertical displacement (Okiemute and Fatai 2018). Some works in literature also discuss Terrestrial Laser Scanning (TLS) for bridge monitoring during load tests (Zogg and Ingensand, 2008, Lõhmus et al., 2018). After the test a new campaign of measurements is carried out to verify the possible onset of permanent deformations. Several NDT methods are currently used for the assessment of the structural condition with respect to possible degrading phenomena or damaging actions. They can be classified in (Hung, et al., 2009) visual, penetrating radiation (e.g. X-ray), magnetic (e.g. eddy currents); mechanical vibrations (e.g. ultrasonic or modal testing), acoustic emissions, chemical/electrochemical methods, thermal (e.g., infrared thermography) and other optical methods (e.g. interferometry).

Most of these techniques are used for short or periodical monitoring since they require the use of instrumentation and sensors that are not permanently installed on the structure.

Common visual inspections are useful for identifying alterations and decays processes and a set of international protocols are available for investigating different types of structures and different materials. Several non-destructive tests such as Sonic Rebound tests are available to detect carbonation depth, chlorides content and corrosion of the steel bars in reinforced concrete (r.c.) structures. Thermographic tests can be employed to assess the adhesion of FRP strips used to retrofit r.c. (Schroeder et al. 2002; Ghosh et al. 2010): these tests are able to identify bonding defects between the adhesive and the substrates and also the possible damage progression (Cantini et al. 2011). For masonry structures, beyond the information about the material characteristic, other information related to the past history of the structure are needed and have to be collected through historical research, geometrical survey, material and decay mapping, crack pattern survey. NDT, like thermovision, radar and sonic measurements can provide indications on the construction techniques and possible anomalies; MDTs such as drilling and video-boroscopy are useful for evaluating the masonry section characteristics; (Minor Destructive Tests) (Helmerich et al. 2008), when complementary used with the previous ones.

The NDTs provide detailed information about a local damage state but require that the vicinity of damage is already known and easily accessible. When information about the global state of the structure is needed, and the location of damage is unknown, these techniques may reveal costly, taking a long time to be applied to the whole structure and they may fail if damage is not visibly evident. A promising alternative, able to provide information on the global structural health consists in the use of responses to vibrations that can be measured during periodic tests in terms of accelerations or displacements. To this aim several types of accelerometers can provide good accuracy and the capability to measure at very low frequencies ( $\mathrm{Li}$ et al., 2018, Cabboi et al., 2017). If displacements do not exceedi a few millimetres, they can be efficiently measured also using ground-based radar interferometry (Diaferio et al., 2017, Zhou et al., 2018). This technique has a high accuracy, but the price does not yet allow its implementation on large scale for practical applications (Pieraccini 2013). Continuous-wave (CW) radar technology is another promising approach to measure structural displacement due to ambient vibrations; it has a reasonable cost compared with other displacement sensors, and it may be very compact, making it easy to install and transport (Guan et al., 2014).

If a network of sensors is permanently deployed on the structure, continuous monitoring can be carried measuring the structural response to vibrations in terms of e.g. acceleration or displacements. Usually accelerometers are used to this aim whereas long term identification of displacements is more challenging and requires an extensive set of instruments (e.g., GPS, TS, levelling network etc.).

Synthetic Aperture Radar Interferometry (InSAR) can be used to monitor displacement on a monthly or weekly time-scale according to the specific satellite used for the analysis. The influence of environmental sources such as temperature on displacements can be observed taking into consideration Persistent Scatterer Interferometry (PSI) displacements time series (Lazecky et al., 2015). However, decomposition of the line-of-sight (LOS) measurements to derive the different components of bridges movements is a non-trivial task. 
Despite several successful applications and important scientific efforts, SHM is not yet extensively used for performance assessment of civil infrastructures. Permanent monitoring systems are usually installed on strategic or landmark structures but suffer from non-scalability due to the not negligible cost of instrumentation devices, installation, and maintenance. Further to this, the difficulty to estimate the return on investment on these systems, before their implementation, creates some reluctance in the stakeholders (from owners to sensors producers) to invest on them. A further issue is related to the lack of incentives in the technical codes that usually do not allow to account for the presence of a structural monitoring system in the design of new bridges or in the retrofit of existing ones. Monitoring systems are thus perceived by stakeholders more as a cost rather than an effective benefit. Recently the research project COST TU1402 on 'Quantifying the Value of Structural Health Monitoring' (Thons et al. 2017) has proposed a framework taking basis on the concept of Value of Information from the pre-posterior Bayesian decision analyses, as a support tool for the cost/benefit analyses of a monitoring system before its deployment. Other efforts of researchers related to Structural Health Monitoring (SHM) are directed toward autonomously operating equipment (e.g. robotics) and non-intrusive observation techniques, or other methods that monitor the structural performance with a high degree of accuracy. Still, several barriers exist for the implementations of robotics, from the technical perspective such as the ability to efficiently perform inspection processes incorporating NDT at an operational environment and integrating the data in the bridge management systems to non-technical aspects related to standardisation, data management, cybersecurity and legal aspects among others. During the past few years, several European projects or actions (IMAC, COST action F3, Sustainable Bridges, Arches, Bridgemon, Infrastar, Infravation...) or US projects as the FHWA's Long-Term Bridge Performance (LTBP) have focused on innovative methods and technologies for performance monitoring.

\section{PERFORMANCE ASSESSMENT}

Data provided by monitoring (any type, from visual inspections to NDTs and permanent monitoring systems) must support the assessment of the structural performance of the monitored bridges under several loading conditions and feed decision making procedures. To this respect an important issue is the integration of the collected data into Bridge Management Systems (BMS). Processing of data provides information about possible damage scenarios (Limongelli 2010, Dilena 2014, Domaneschi et al. 2016), or about parameters that can be used to calibrate performance models able predict the remaining service life of the bridge. Not least, data provide information in support of the implementation of optimal maintenance strategies that minimize the maintenance effort while maximizing safety, service lifetime and functionality. The information that have to be extracted from data and used for decision making, depends on the goal of monitoring. To this aim performance indicators can be defined to describe the performance of the bridge with respect to different phenomena that influence to goal to reach. These indicators maybe related for example to durability, to reliability, to availability, etc. In order to compute the performance indicators, monitoring data have to be processed. Data fusion techniques can be used to combine information from multiple sensors and technologies in order to improve the overall performance of damage identification algorithms. (Sbartaï, et al., 2012) mention that measurements performed through NDTs of physical parameters such as the velocity of ultrasonic waves, the electrical resistivity or GPR (Ground Penetrating Radar) the wave attenuation, are disturbed by uncertainties. These can be introduced by various causes such as the low accuracy and repeatability of the measurement process, the variability of the material at different scales and the influence of environmental sources such as moisture or temperature. To reduce these uncertainties several different techniques can be combined to compute a performance indicator. As an alternative, the combination of several NDT parameters obtained with the same technique (Sbartaï, et al., 2012), (Zaid, et al., 2004), can confirm an information (for example the diagnosis about a certain damage of a certain severity) or reduce the measurement noise. (Villain, et al., 2012).

Another issue related to data collected by permanent monitoring systems is that, even small systems, produce large amount of data. The concept of 'Big Data' is described by 3Vs: Volume, Variety and Velocity that is related to large volumes of data from a variety of data sources which are available at high velocity. The amount of data flow can be an issue for the storage and processing of data that can hardly be handled and interrogated using traditional techniques. On the other hand, large amounts of data increase the chances to have a reliable estimation of the performance parameters, provided a proper processing of these data is available. Large amount of data may reveal correlations and dependencies that allow to perform predictions of outcomes and behaviours thus fostering informed and rational decision-making for an efficient management of the structure. Thanks to improvements in sensing capabilities, processing power, storage capacity, software programs and quality of internet connections, the capability of capturing, collecting, sharing, storing and processing massive amount of data is steadily increasing giving the opportunity to take advantage of very large Volumes of a wide Variety of data collected and analysed at high-Velocity.

Big Data can be supplied to Machine Learning (ML) algorithms that can 'learn' from data without having been explicitly programmed for that purpose. ML algorithms and statistical models detect patterns from data based on data mining, pattern recognition and predictive analysis. They are much more effective to deal with uncertainties, with respect to traditional algorithms, in situations where large and diverse datasets (i.e. Big Data) are available. Due to the large volumes of data the analyses and the detection of the correlations and relationships between thee data might be prohibitive using traditional methods. Machine learning algorithms, such as for example Artificial Neural Networks, are based on the training of a model using available data (Farrar \& Worden 2013). If data about different performances of a bridge are available (for example the response of the bridge in different damage states) 'supervised' algorithms based on regression, classification and pattern recognition, can be used. If only data relevant to a reference state, for example the undamaged state, are known, 'unsupervised' algorithms that detect deviations from the reference state, without providing further information about the damage state (e.g. type or severity) can be used. Machine learning, together with pattern recognition and deep learning, are branches of the so-called Artificial Intelligence (AI) techniques that can be defined as the ability of a machine to mimic intelligent human behaviour, seeking to use humaninspired algorithms to solve problems (Penadés et al. 2016, Amezquita-Sanchez et al. 2016).

All the aforementioned techniques aim to process recorded data in the most effective way in order to retrieve directly, or using numerical or analytical models, indicators of the structural performance that canbe used, together with assigned 
performance goals, to assess the structural performance. In the next section a survey of the current research trends regarding performance indicators and models to estimate their evolution under forecasted values of the external actions is reported.

\section{PERFORMANCE INDICATORS AND MODELS}

Bridge management strategies rely on maintenance actions to keep assets at a desired performance level. As remarked in the previous section, in the last years, significant research efforts have been devoted on the use of data provided by NDTs, continuous monitoring systems and visual inspection techniques for condition assessment of bridge (Limongelli et al 2018). Data provide information on the structural condition that is then compared with previously established goals. Recently, the concept of performance indicators was introduced, simplifying the communication between consultants, operators and owners. These indicators can be qualitative or quantitative based, and they can be obtained during principal inspections, through a visual examination, a non-destructive test or a temporary or permanent monitoring system. Once obtained, the indicators are compared with predefined performance goals, in order to evaluate if the quality control plan is accomplished. There is a large disparity in Europe regarding the way these indicators are quantified and how such goals are specified. In order to tackle this issue, the COST Action TU1406 on 'Quality Specifications for roadway bridges, standardization at a European level' (Matos, 2016), recently concluded, collected performance indicators used in 31 European countries in order to investigate the possibility to propose a common framework for the quality check of short to medium span road bridges. In this framework, performance indicators are the basic elements to assess the structural performance. For performance indicators the issue of extreme events is not thoroughly assessed (Prendergast et al. 2018). To this aim, recently detailed studies on risk analysis with respect to extreme events have been performed. The aim is to provide a more accurate assessment of risk and to use it as a performance indicator describing the structural behavior with respect to extreme events. Some studies can be found in (Decò and Frangopol 2011). Another performance indicator associated to extreme events, that has recently received attention from many researchers, is the resilience of infrastructures. Resilience interpreted qualitatively as a systems ability to plan for, recover from and adapt to adverse events over time (Mc Allister 2013, NAS 2012, Faber et al. 2017, Faber 2019, Gardoni 2019) .

Performance models present a critical part of a management system by predicting along the time the future behavior of an infrastructure under forecasted values of the external action. In literature are proposed both deterministic and probabilistic performance models. The latter have been assuming greater importance in the scientific community since the deterministic models cannot consider the uncertainties of the variables. A large part of the probabilistic models is based on Markov chains (Devaraj 2009, Ferreira, Neves et al. 2014, Mirzaei, Adey et al. 2014, Denysiuk, Fernandes et al. 2016), in which the degradation is accounted for through a set of probability distribution in relation to the evolution of the condition states. The main reason behind the choice and use of Markov chains dwells in the simplicity of work with the available data (Morcous 2000). On the other hand, these models present some limitations, such as their memoryless property, that makes each stage only dependent on the previous stage ignoring older ones. or this reason alternative models to the classic Markov such as Hidden-Markov Chains and Semi-Markov Chains have been proposed. Recently, and with applications to fields like railway bridges, Petri Net models have demonstrated the appropriateness to model the infrastructure performance (Yianni et al. 2017). Other options of performance modeling, as remarked in section 3, rely on artificial intelligence based on neural networks. Neural evolution is a method to train neural networks through evolutionary algorithms. One of the disadvantages of these methods is management of the amount of data these methods provide (Floreano, Dürr et al. 2008). Some applications can be seen in (Huang 2010). All the models previously described reveal to be a very good option to model the structural performance in infrastructure management systems, if appropriate data are available to calibrate them. Their drawback is that they only consider the progressive degradation processes, i.e. caused by processes as corrosion, carbonation, cracking and creep therefore the effect of extreme event, as already mentioned regarding performance indicators, cannot be accounted for. Yet, due to the large consequences extreme events may produce, and considering their increased frequency related to climate change, there is a urgent need to include them in the performance models. Several authors have proposed shock models that allow to include the effects of extreme events through parameters related to their return period. Some of these studies, can be found in references (Huang 2010, Sanchez-Silva, Klutke et al. 2012). Along this topic, several research projects have been developed. In the USA, the NCHRP - National Cooperative Highway Research Programs developed works in the field of life-cycle analysis, optimisation and decision-making process. In Europe, some projects were also developed such as Sustainable Bridges, COST TU1406, LIFECON, DARTS, SustIMS, INNOTRACK, RAGTIME among others.

\section{STANDARDIZATION FOR INFRASTRUCTURE MANAGEMENT}

Asset management depends on well-defined rules and standards for general application. A standards document is a harmonized procedure agreed by all relevant stakeholders. The trend in international standardization leads towards framework standards which specify the basic procedures and leave the details either to national codes or to the parties applying it. Bridge management is currently regulated on national level and it is desirable to achieve approaches that produce comparable results in order to support the idea of equal quality on the European Transnational Corridors. Standards represent the state of the art and practice. In special cases the state of science and technology has also to be considered. It can reasonably be assumed that designers and contractors working on special projects are aware of the latest development in their sector. As standards undergo a lengthy process to become valid (on average more than 10 years) science and technology might have considerably progressed making previous rules and assumptions invalid.

However, there are several arguments for applying standardized frameworks such as:

- Going from national to global markets, we require comparable approaches in order to be able to satisfy the foreign set of rules. In the European context it is also desirable to find equal quality standards all over the continent.

- Frameworks make works comparable and allow ranking of interventions. Doing that, international know-how can be directly applied and supports and sharpens one's own approach.

- In times of insufficient budgets, it will be easier to focus on projects that are highly ranked in the priority list. Decisions on future budget allocation become feasible.

- Standards provide the basis for juridical safe environments for 
operators and the related expert community. As explained above, standards alone do not satisfy this.

- Standardized procedures allow competition which will lead to more economic projects. Standardized products and procedures are more often applied and therefore lower budget for inherited risks will be considered.

- Standardized approaches will allow suppliers to develop economic products based on the potentially higher numbers of sales.

On the other hand, standards do not restrict owners beyond reasonable requirements. This can be expressed by:

- Any standard can be excluded if it does not fit as explained above. Standards are for standard cases and specific cases have to be treated differently.

- Every nation still has the power to issue nationally determined parameters (NDPs) to fit the framework for any specific application or case.

- Nationally determined parameters are necessary anyway for spatial-related hazards or loads such as seismicity, snow loads or wind regimes. Major attention shall also be put on the temperature effects on structures in each area.

- The mentioned standards do not restrict the use of any Application-Specific specific rule for visual inspections or the use of monitoring results in the assessment process. Advanced regulations such as the Austrian RVS 13.03.11 allow the case-specific determination of inspection intervals in case that uncertainties are reduced by monitoring results. This procedure is also supported by the new Eurocode EN 16991:2018. Once again standards are for standard cases only. For special cases engineering and expert knowledge shall be applied as quoted in EN1990 on page 7.

Considering the above-mentioned facts, it becomes not only beneficial but rather necessary to get the necessary expertise on current know-how in order to be safe from being tried.

Bridge management does not know one specific standard for relevant performance. Currently most European countries apply the rules that have been developed in the 1980s created after the prominent collapses (i.e. the Reichsbrücke in Vienna on 1 August 1976). They were made before the Eurocodes became ready for practice. The main basis has been the results of visual inspection which documented a subjective rating. This rating has been subsequently refined, and a specific structural condition has been connected to the values.

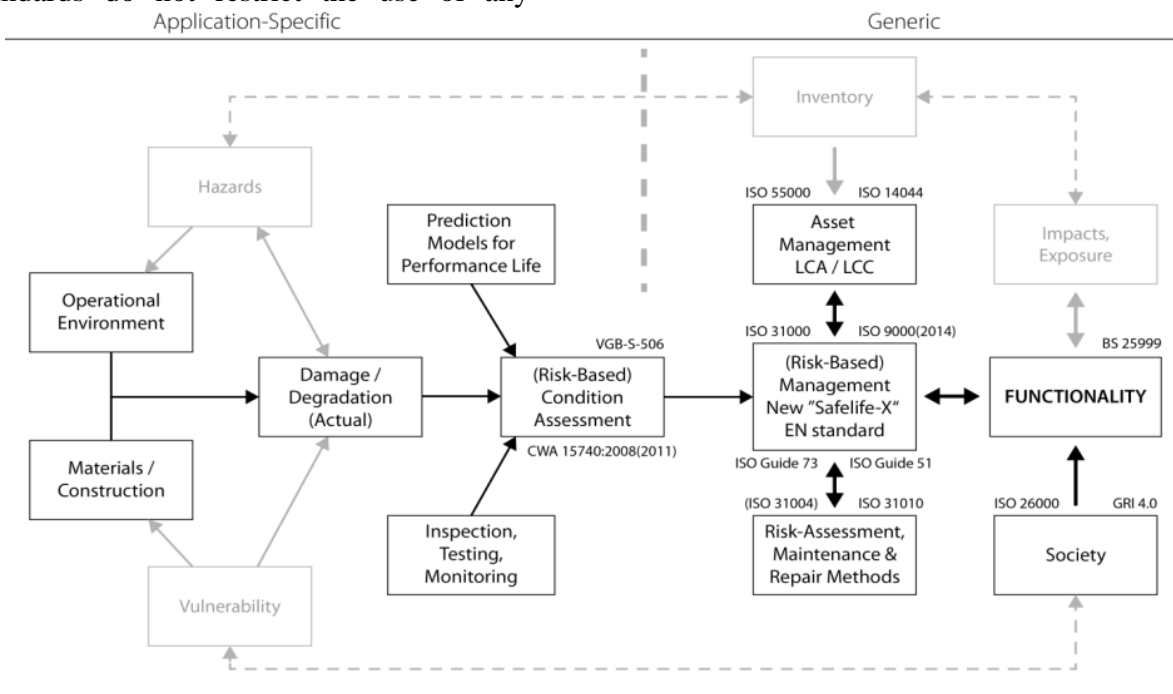

Figure 2. Typical framework for risk-based asset management

With the introduction of performance-based design approaches the procedure requires more information to become usefully applicable. With sustainability and resilience becoming desired performance criteria, the procedure had to include risk-based elements. From the previous simple determination of probability of occurrence, the consequences of performance have to be considered. This brings indicators on economy, environment and society into the procedures. The step from simple deterministic ways towards probabilistic approaches is inevitable. On the other hand, the older our structures get, the less the previous procedures produce credible results. The new tools allow dealing with structures built a long time ago under very different specifications to fit into nowadays' frameworks.

The currently available valid standards on a global scale allow to implement a management procedure divided into a generic and a project-specific domain. Figure 2 represents such a case elaborated for industries where structures also play a major role. There is the intention to adopt it to the very specific requirements of bridge management. The main standards here highlighted are:
- ISO 55000: basics framework for asset management;

- ISO 31000: risk management framework;

- Eurocodes EN1990 to EN1998: cover the indicators for safety and durability. They are currently under further development in the direction of performance-based asset management;

- EN 16991:2018: addressing the risk-based inspection topic. It also contains the mathematical formulation of ageing (degradation) which has been developed and derived from a perfect set of bridge performance over a period of 45 years (Figure 3);

- ISO 21929-2: focusing on sustainability of civil construction works is developed. A major number of other standards are necessary to complete the procedure. They may comprise operational safety, impact on environment on the structure, security guidelines, quality specifications and project-specific definitions. This is the reason why the European Commission and other global science funding agencies have supported a number of projects, particularly in the bridge domain. The most prominent ones are the following two:

- The Long-Term Bridge Performance Project (LTBP) in the 
United States started in 2012, has a scheduled duration of 10 years and a budget of 200 million USD. It is controlled and funded by the Federal Highway Agency (FHWA) with the objectives to better understand bridge performance and finally to achieve more robust bridges. FHWA operates the National Bridge Inventory (NBI) covering a total of about 620,000 bridges. This huge database is perfectly conditioned for the application of risk performance-based tools. Going from structural to element level a tool using the European development of the ageing curve has been already implemented and tested.

- The Structural Integrity Program (SIP) in Japan has been

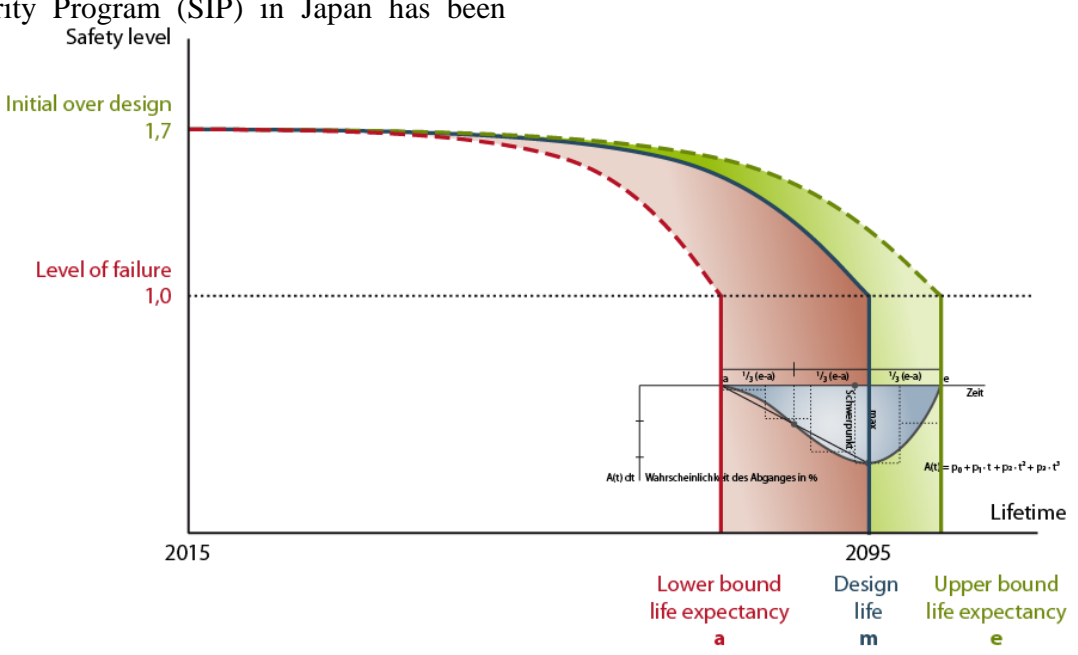

Figure 3. Mathematical formulation of degradation as specified by EN 16991

\section{CONCLUSIONS}

In this paper a survey of the current research efforts in the field of lifecycle management of large infrastructures is reported, highlighting needs and challenges toward a safe, resilient and sustainable development of the procedures currently implemented. Future developments that could foster the evolution of large infrastructure management toward these goals shall include:

- A comfortable open GIS surface and platform. This allows comparable approaches, overlapping work at national borders and enables the application of the many, very useful tools developed in specific smaller European projects.

- Building Information Models (BIM) become more and more standard practice. Some bridge owners already demand any future activity in this framework (e.g. DB Deutsche Bahn). There is a standardization drive for BIM on ISO level where the Chinese Academy of Science is trying to establish a leading function. Nevertheless, the basis for BIM is still laid in Europe. A major advantage of applying such models would be that for future monitoring campaigns supporting the reduction of uncertainties the relevant structural models could be easily extracted. This is highly desirable.

- On the economy side there is no alternative to life-cycle approaches. Relevant standards of the 16000 series but also for environment and economics the 13000 and 14000 series provide helpful tools for our cases.

- Risk-based procedures are not yet common practice. However, with the first application in EN 16991 the charm of these approaches will quickly be recognized, and further development is expected.

- Sustainability-driven application considering the so-called soft factors economy, environment and society as specified in ISO 21929-2 will help to bridge the gap to applications in difficult environments. launched by the Ministry of Construction in order to ensure safe operation of bridges in Japan. The budget of 40 million USD has been used to improve inspection procedures, to develop robotic applications like drones and to modernize and improve applicable regulations for structural assessment. The final results are presented in December 2018.

Both large projects take European development and make applications on a large scale. We are definitely missing such an initiative in Europe.
International science funding agencies have supported a number of projects, particularly in the bridge domain that make applications on a large scale. We are definitely missing such an initiative in Europe.

\section{ACKNOWLEDGEMENTS}

The networking support of COST Action TU1402 on 'Quantifying the Value of Structural Health Monitoring' and of COST Action TU1406 on 'Quality specifications for roadway bridges, standardization at a European level (BridgeSpec)'

\section{REFERENCES}

Amezquita-Sanchez, J., Valtierra-Rodriguez, M., Aldwaik, M. Adeli, H., 2016. Neurocomputing in civil infrastructure. Sci Iran Trans C Chem Chem Eng 2016;23:2417.

Austrain Standard RVS 13.03.11. Guideline on bridge inspection. bmvit, 2011. Forschungsgesellschaft für das Verkehrs- und Straßenwesen: RVS 13.03.11 Überwachung, Kontrolle und Überprüfung von Kunstbauten - Straßenbrücken. Vienna, 2011.

Cabboi, A., Magalhães, F., Gentile, C., Cunha, Á., 2017. Automated modal identification and tracking: Application to an iron arch bridge. Structural Control and Health Monitoring, 24(1), e1854.

Cimellaro, G., 2013. Resilience-based design (RBD) modelling of civil infrastructure to assess seismic hazards. Handbook of Seismic Risk Analysis and Management of Civil Infrastructure Systems, Elsevier: 268-303.

Cantini, L., Cucchi, M., Fava, G., Poggi, C., 2013. Damage and 
Defect Detection Through Infrared Thermography of Fiber Composites Applications for Strengthening of Structural Elements, In Buyukozturk O., Tasdemir M. A., Gunes O., Akkaya Y. (eds), Nondestructive Testing of Materials and Structures, Vol II, Springer, 779-784.

Decò, A., Frangopol, D. M., 2011. Risk assessment of highway bridges under multiple hazards. In Journal of Risk Research 14(9), 1057-1089.

Denysiuk, R., Fernandes, Matos, Neves, L. C., Berardinelli, U., 2016. A computational framework for infrastructure asset maintenance scheduling. In Structural Engineering International 26(2), 94-102.

Devaraj, D., 2009. Application of non-homogeneous Markov chains in bridge management systems, Wayne State University.

Diaferio, M., Fraddosio, A., Piccioni, M. D., Castellano, A., Mangialardi, L., Soria, L., 2017. Some issues in the structural health monitoring of a railway viaduct by ground based radar interferometry. In 2017 IEEE Workshop on Environmental, Energy, and Structural Monitoring Systems (EESMS) (pp. 1-6). IEEE.

Dilena, M., Limongelli, M.P. Morassi, A., 2014. Damage localization in bridges via FRF interpolation method. Mechanical Systems and Signal Processing, 52-53, pp 162-180.

Eurocode EN 16991:2018 on Risk-based inspection framework.

EN 1990:2002. Eurocode - Basis of structural design.

EN 1998: Design of structures for earthquake resistance.

Faber, M. H., 2019. On sustainability and resilience of engineered systems. In Routledge Handbook of Sustainable and Resilient Infrastructure, edited by Paolo Gardoni, 28-49. New York: Routledge.

Faber, M. H., Qin J., Miraglia, S., Thönsn S., 2017. On the probabilistic characterization of robustness and resilience. Procedia engineering 198, 1070-1083.

Farrar, C., Worden, K., 2013. Structural Health Monitoring: a machine learning perspective. J. Wiley \& Sons Ltd.

Ferreira, C., Neves L. C., Matos J. C., Soares, J. M. S., 2014. A degradation and maintenance model: Application to Portuguese context. Proceedings of Bridge Maintenance, Safety, Management and Life Extension, 483-489.

Floreano, D., Dürr, P., Mattiussi, C., 2008. Neuroevolution: from architectures to learning. In Evolutionary Intelligence 1(1), 47-62.

Frýba, L., and Pirner, M., 2001. Load tests and modal analysis of bridges. Engineering Structures, 23(1), 102-109.

Gardoni, P. (Ed.), 2019. Routledge Handbook of Sustainable and Resilient Infrastructure, edited by Paolo Gardoni. New York: Routledge.

Ghosh, K.K., Karbhari, V.M., 2010. Use of infrared thermography for quantitative nondestructive evaluation in FRP strengthened bridge systems. Int. J Mater Prod Technol, 1-17.
Guan, S., Rice, J. A., Li, C., Gu, C. 2014. Automated DC offset calibration strategy for structural health monitoring based on portable $\mathrm{CW}$ radar sensor. IEEE Transactions on Instrumentation and Measurement, 63(12), 3111-3118.

Hadi, S., Burguegno, R., 2018. Emerging artificial intelligence methods in structural engineering Engineering Structures 171, pp. $170-189$

Helmerich, R., Trela, C., Brien, J., Bernardini, G., 2008. Complex multi-tool inspection of masonry arch bridges using non-destructive testing. In: Proceedings of the fourth International Conference on Bridge Maintenance, Safety and Management, July 13-17, 2008. Seoul, Korea. Leiden, Netherlands: CRC Press/ Balkema, 3716-3723.

Ko, J. M. and Ni, Y. Q., 2005. Technology developments in structural health monitoring of large-scale bridges. Engineering structures, 27(12), 1715-1725.

Huang, Y.-H., 2010. Artificial neural network model of bridge deterioration. In Journal of Performance of Constructed Facilities 24(6), 597-602.

ISO 31000:2018, Risk management - Guidelines

ISO 55000:2014. Asset Management standards.

ISO/TS 21929-2:2015. Sustainability in building construction -Sustainability indicators -- Part 2: Framework for the development of indicators for civil engineering works.

Lazecky, M., Perissin, D., Bakon, M., de Sousa, J. M., Hlavacova, I., Real, N., 2015. Potential of satellite InSAR techniques for monitoring of bridge deformations. In 2015 Joint Urban Remote Sensing Event (JURSE) (pp. 1-4). IEEE.

Li, X. Z., Wang, M., Xiao, J., Zou, Q. Y., Liu, D. J., 2018. Experimental study on aerodynamic characteristics of highspeed train on a truss bridge: A moving model test. Journal of Wind Engineering and Industrial Aerodynamics, 179, 26-38.

Limongelli, M.P., 2010, Frequency Response Function Interpolation for Damage Detection under Changing Environment Mechanical Systems and Signal Processing, 24(8), 2898-2913.

Limongelli, M.P, Chatzi, E., Anzlin, A, 2018. Condition assessment of roadway bridges: from performance parameters to performance goals. The Baltic Journal of Road and Bridge Engineering 2018/13(4). ISSN 1822-427X/eISSN 1822-4288 2018 Volume 13 (4), 345-356. https://doi.org/10.7250/bjrbe.2018-13.421

Liu, M., and Frangopol, D. M., 2005. Multiobjective maintenance planning optimization for deteriorating bridges considering condition, safety, and life-cycle cost. Journal of Structural Engineering, 131(5), 833-842.

Lõhmus, H., Ellmann, A., Märdla, S., Idnurm, S., 2018. Terrestrial laser scanning for the monitoring of bridge load tests-two case studies. Survey Review, 50(360), 270-284.

Lounis, Z., McAllister, T. P., 2016. Risk-based decision making 
for sustainable and resilient infrastructure systems. In Journal of Structural Engineering 142(9), F4016005.

Marjanishvili, S., Quiel, S., Katz B., 2014. A performancebased framework for structural resilience to blast-induced damage. In Journal of Structural Engineering 142(8),22-29, DOI: $10.5703 / 1288284315348$

McAllister, T., 2013. NIST Technical Note 1795: Developing Guidelines and Standards for Disaster Resilience of the Built Environment: A Research Needs Assessment. U.S. Department of Commerce.

Matos, J., 2016. An overview of COST Action TU1406. Quality specifications for roadway bridges (BridgeSpec). Proc. of the $5^{\text {th }}$ International Symposium on Lifecycle Civil Engineering, Delft, The Netherlands.

Mirzaei, Z., Adey, B. T., Thompson, P., Klatter, L., 2014. Overview of existing Bridge Management Systems-Report by the IABMAS Bridge Management Committee (2014). 7th International Conference on Bridge Maintenance, Safety and Management (IABMAS 2014), International Association for Bridge Maintenance And Safety (IABMAS).

Morcous, G., 2000. Case-based reasoning for modeling bridge deterioration, Concordia University.

Moreu, F., Li, J., Jo, H., Kim, R. E., Scola, S., Spencer Jr, B. F., LaFave, J. M., 2015. Reference-free displacements for condition assessment of timber railroad bridges. Journal of Bridge Engineering, 21(2), 04015052.

NAS 2012. National Research Council Disaster Resilience: A National Imperative, The National Academies Press, 2012.

Okiemute, E. S., Fatai, O. O., 2018. Monitoring and Analysis of Vertical Deformation of Palm House Benin City Using Digital Level. International Journal of Advances in Scientific Research and Engineering, 4.

Ouyang, M., Dueñas-Osorio, L. and Min, X., 2012. A threestage resilience analysis framework for urban infrastructure systems. In Structural Safety, Elsevier, 2012, Vol. 36, p.23-31.

Penadés-Plà, V., García-Segura, T., Martí J.V., Yepes, V., 2016. A review of multi-criteria decision-making methods applied to the sustainable bridge design. Sustainability $2016 ; 8,1295$.

Pieraccini, M., 2013. Monitoring of civil infrastructures by interferometric radar: A review. The Scientific World Journal, 2013.

Prendergast Luke J., Limongelli M.P., Ademovic N., Anžlin A., Gavin K., Zanini M., 2018. Structural Health Monitoring for Performance Assessment of Bridges under Flooding and Seismic Actions, Structural Engineering International, DOI: 10.1080/10168664.2018.1472534.

Sanchez-Silva, M., Klutke, G.-A., Rosowsky, D. V., 2012. Optimisation of the design of infrastructure components subject to progressive deterioration and extreme loads. Structure and Infrastructure Engineering 8(7), 655-667.

Sbartaï, Z., Breysse, D., Larget, M. \& Balayssac, J., 2012. Combining NDT techniques for improving concrete properties evaluation. Cement and Concrete Composites, 34(6), pp. 725733.

Schroeder, J.A., Ahmed, T., Chaudhryb, B. Shepard, S., 2002, Non-destructive testing of structural composites and adhesively bonded composite joints: pulsed thermography. Comp A, vol. 33 (11), 1511-1517.

Tang, X., Roberts, G. W., Li, X., Hancock, C. M., 2017. Realtime kinematic PPP GPS for structure monitoring applied on the Severn Suspension Bridge, UK. Advances in Space Research, 60(5), 925-937.

Thöns, S., Limongelli, M.P., Mandic Ivankovic, A., Val, D., Chryssanthopoulos, M., Lombaert, G., Döhler, M., Straub, D., Chatzi, E., Köhler, J., Wenzel, H., Sørensen, J., 2017. Progress of the COST Action TU1402 on the Quantification of the Value of Structural Health Monitoring. Proc of the IWSHM 2017. The 11th International Workshop on Structural Health Monitoring. September 12-14, 2017, Stanford, California, USA

Villain, G. Sbartai, Z. M., Derobert X., Garnier, V., Balaysac J. P., 2012. Durability diagnosis of a concrete structure in a tidal zone by combining NDT methods: laboratory tests and case study. Construction and Building Materials, 37: 893-903.

Wong, K. Y., 2007. Design of a structural health monitoring system for long-span bridges. Structure and Infrastructure Engineering, 3(2), 169-185.

Xi, R., Jiang, W., Meng, X., Chen, H., Chen, Q., 2018. Bridge monitoring using BDS-RTK and GPS-RTK techniques. Measurement, 120, 128-139.

Yianni, P. C., Rama, D., Neves, L. C., Andrews, J. D., Castlo, D., 2017. A Petri-Net-based modelling approach to railway bridge asset management. Structure and Infrastructure Engineering 13(2), 287-297.

Yu, Z. W., Mao, J. F., Guo, F. Q., Guo, W., 2016. Nonstationary random vibration analysis of a 3D train-bridge system using the probability density evolution method. Journal of Sound and Vibration, 366, 173-189.

Zaid, M., Gaydecki, P., Quek, S., Miller, G., Fernandes, B., 2004. Extracting dimensional information from steel reinforcing bars in concrete using neural networks trained on data from an inductive sensor. NDT \& E International, 37(7), 551-558.

Zhou, H. F., Ni, Y. Q., Ko, J. M., 2006. Analysis of structural health monitoring data from the suspension Jiangyin Bridge. In Proceeding of the $3 r$ European workshop on structural health monitoring (pp. 364-371).

Zhou, L., Guo, J., Hu, J., Ma, J., Wei, F., Xue, X., 2018. Subsidence analysis of ELH Bridge through ground-based interferometric radar during the crossing of a subway shield tunnel underneath the bridge. International journal of remote sensing, 39(6), 1911-1928. 